\title{
(Q) Cholesterol ester transfer protein inhibition by TA-8995 in patients with mild dyslipidaemia (TULIP): a randomised, double-blind, placebo-controlled phase 2 trial
}

\author{
G Kees Hovingh, John JP Kastelein, SanderJ H van Deventer, Patrick Round, John Ford, Danish Saleheen, DanielJ Rader, H Bryan Brewer, PhilipJ Barter
}

\section{Summary}

Lancet $2015 ; 386: 452-60$

Published Online

June 3, 2015

http://dx.doi.org/10.1016/

S0140-6736(15)60158-1

See Online/Comment

http://dx.doi.org/10.1016/

S0140-6736(15)60608-0

Department of Vascular

Medicine, Academic Medical

Center, University of

Amsterdam, Netherlands

(G K Hovingh,

Prof JJ P Kastelein); Dezima

Pharma BV, Naarden,

Netherlands (Prof JJP Kastelein,

Prof SJ H van Deventer, P Round,

J Ford); Department of

Gastroenterology, Leiden

University Medical Centre,

Leiden, Netherlands

(Prof SJ H van Deventer);

Xention, Cambridge, UK

(P Round, J Ford); Department

of Genetics, Perelman School of

Medicine, University of

Pennsylvania, PA, USA

(D Saleheen, Prof D J Rader);

MedStar Research Institute,

Washington Hospital Center,

Washington DC, USA

(Prof H B Brewer); and Centre for Vascular Research,

University of New South Wales,

Sydney, NSW, Australia

(Prof PJ Barter)

Correspondence to:

Dr G Kees Hovingh, Department

of Vascular Medicine, Academic

Medical Center University of

Amsterdam, 1105 AZ Amsterdam,

Netherlands

j.s.jansen@amc.nl unacceptably high risk of having a future cardiovascular event despite treatment with optimum doses of effective statins and other lipid lowering treatments. Although the residual risk relates (at least partly) to factors other than plasma lipids, in many patients the concentration of LDL cholesterol remains high despite statin treatment. This finding has stimulated a major effort to develop drugs that provide additional lowering of LDL cholesterol when coadministered with a statin.

Several LDL cholesterol-lowering strategies are being investigated, and inhibitors of cholesteryl ester transfer protein (CETP), by virtue of their effect on the transfer of cholesterol into atherogenic LDL particles, ${ }^{2}$ reduce LDL cholesterol levels.

Initial attempts to show cardioprotective effects of CETP inhibition with torcetrapib and dalcetrapib in human beings have failed.,4 Nevertheless, the hypothesis of a beneficial effect of CETP lowering is being tested in two large clinical outcome trials (REVEAL [NCT01252953] and ACCELERATE [NCT01687998]) in which investigators are studying CETP inhibitors that do not possess the adverse off-target effects of torcetrapib.

In a phase 1 study $^{5}$ in human beings, TA-8995, a novel inhibitor of CETP, exerted potent effects on both pro-atherogenic and anti-atherogenic lipoprotein particles, without the off-target effects of torcetrapib.

We aimed to assess the safety and efficacy of TA-8995 as monotherapy and combined with statins in patients with mild dyslipidaemia. 


\section{Methods}

\section{Study design and participants}

In this randomised, double-blind, placebo-controlled, parallel-group phase 2 trial, we recruited men and women (aged 18-75 years) from 17 sites (hospitals and independent clinical research organisations) in the Netherlands and Denmark with fasting LDL cholesterol levels between $2.5 \mathrm{mmol} / \mathrm{L}$ and $4.5 \mathrm{mmol} / \mathrm{L}$, HDL cholesterol levels between $0.8 \mathrm{mmol} / \mathrm{L}$ and $1.8 \mathrm{mmol} / \mathrm{L}$ and triglyceride levels below $4.5 \mathrm{mmol} / \mathrm{L}$ after run-in, or washout of previous lipid-lowering treatments. Key exclusion criteria included clinical manifestations of atherosclerotic vascular disease, type 1 diabetes, uncontrolled type 2 diabetes (haemoglobin $A_{1 c} \geq 8 \%$ ), uncontrolled hypertension, history of hyperaldosteronism, active muscle disease or persistent creatine kinase more than three times the upper limit of normal, clinically significant renal or hepatic dysfunction, or evidence of any other clinically significant non-cardiac disease.

The study was in compliance with the ethical principles in the Declaration of Helsinki, the International Conference on Harmonisation/Good Clinical Practice, and appropriate regulatory requirements. The protocol was reviewed and approved by the Institutional Review Board of each participating centre and each patient provided written informed consent.

\section{Randomisation and masking}

We randomly assigned (1:1) patients to receive one of the following nine treatments: $1 \mathrm{mg}, 2.5 \mathrm{mg}, 5 \mathrm{mg}$, or $10 \mathrm{mg}$ TA-8995 or matching placebo; $10 \mathrm{mg}$ TA- 8995 plus $20 \mathrm{mg}$ atorvastatin, $10 \mathrm{mg}$ TA- 8995 plus $10 \mathrm{mg}$ rosuvastatin, $20 \mathrm{mg}$ atorvastatin, or $10 \mathrm{mg}$ rosuvastatin. Patients were assigned to treatment regimens with a computergenerated randomisation schedule coordinated by a centralised computer system. Treatment allocation process was by minimisation. Trial treatments were supplied as TA-8995 capsules and matching placebos. Additionally, atorvastatin and rosuvastatin were overencapsulated and all patients whose treatment did not include a statin were also given a matching placebostatin to maintain masking. During the trial, the patients and all trial-related personnel were masked to individual results of fasting lipid profile measurements, with the exception of safety alerts which were sent to an independent safety group handling all safety-related issues during the trial.

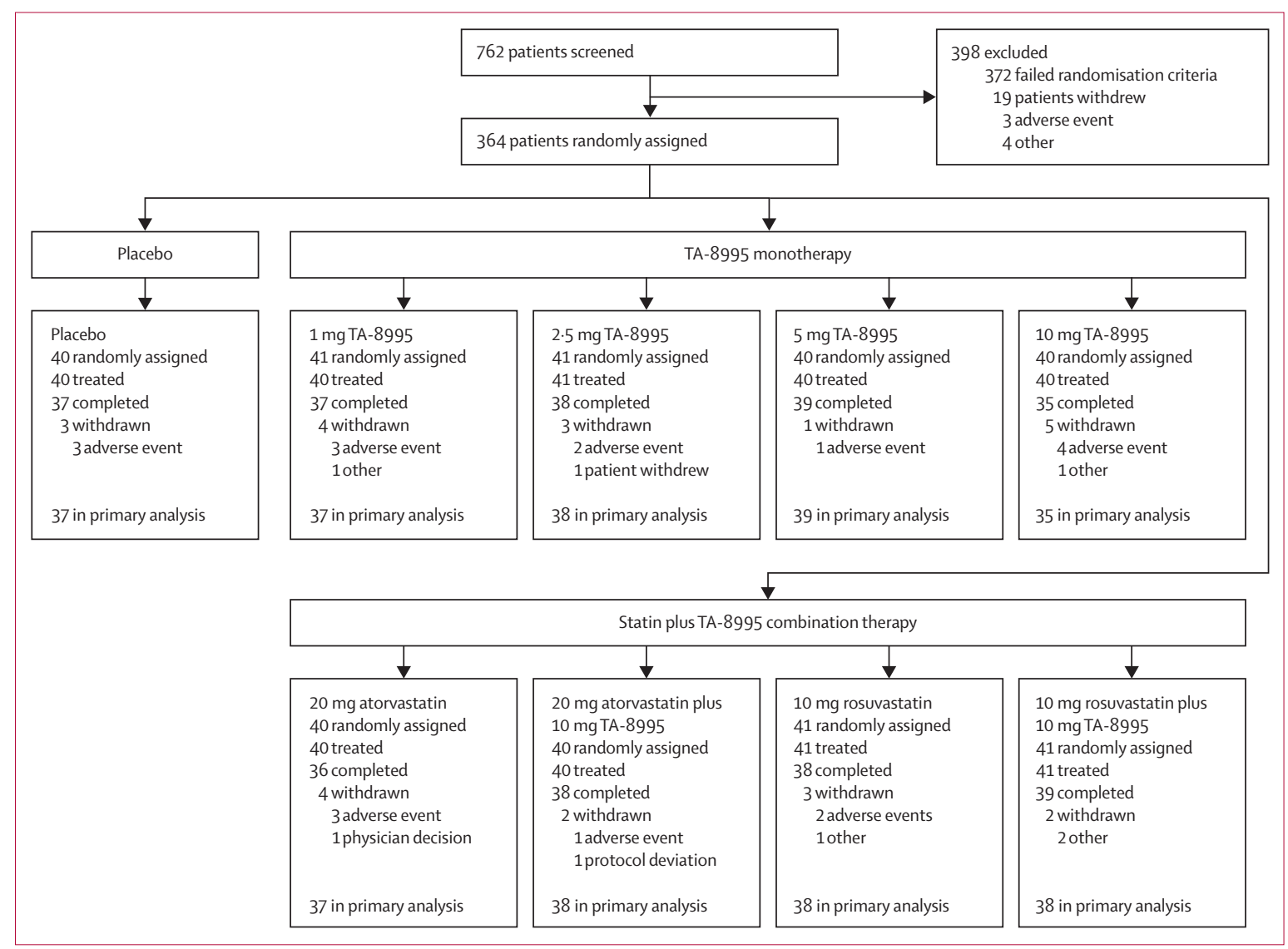

Figure 1: Trial profile

The primary efficacy dataset included all patients who received at least one dose of study drug and had lipid measurements at baseline and week 12 . All patients who received at least one dose of study drug were included in the safety analyses. 


\section{Procedures}

The TULIP study comprised a screening visit, followed by a run-in phase of 4 weeks (or 6 weeks for patients who needed washout of lipid-lowering treatment). All See Online for appendix treatments were to be taken once a day with food for 12 weeks. During the double-blind treatment phase, visits were done at baseline (week 0 ) and at weeks 4,8 and 12. Follow-up visits were done 2 and 8 weeks after the end of treatment. A data safety monitoring board ensured an independent review of safety-related variables during the trial. The appendix shows details of the assay methods.

\begin{tabular}{|c|c|c|c|c|c|c|c|c|c|}
\hline & $\begin{array}{l}\text { Placebo } \\
(n=40)\end{array}$ & $\begin{array}{l}1 \mathrm{mg} \\
\mathrm{TA}-8995 \\
(\mathrm{n}=41)\end{array}$ & $\begin{array}{l}2 \cdot 5 \mathrm{mg} \\
T A-8995 \\
(n=41)\end{array}$ & $\begin{array}{l}5 \mathrm{mg} \\
\mathrm{TA}-8995 \\
(\mathrm{n}=40)\end{array}$ & $\begin{array}{l}10 \mathrm{mg} \\
\text { TA-8995 } \\
(\mathrm{n}=40)\end{array}$ & $\begin{array}{l}20 \mathrm{mg} \\
\text { atorvastatin } \\
\text { plus placebo } \\
(\mathrm{n}=40)\end{array}$ & $\begin{array}{l}20 \mathrm{mg} \\
\text { atorvastatin } \\
\text { plus } 10 \mathrm{mg} \\
\text { TA-8995 } \\
(\mathrm{n}=40)\end{array}$ & $\begin{array}{l}10 \mathrm{mg} \\
\text { rosuvastatin } \\
\text { plus placebo } \\
(\mathrm{n}=41)\end{array}$ & $\begin{array}{l}10 \mathrm{mg} \\
\text { rosuvastatin } \\
\text { plus } 10 \mathrm{mg} \\
\text { TA-8995 } \\
(\mathrm{n}=41)\end{array}$ \\
\hline Age (years) & $64 \cdot 4(6 \cdot 6)$ & $65 \cdot 8(6 \cdot 3)$ & $65 \cdot 5(6.9)$ & $64.9(7.8)$ & $66.0(5.0)$ & $64.0(9.4)$ & $63 \cdot 3(9 \cdot 1)$ & $64.7(8.0)$ & $63.8(6.1)$ \\
\hline Sex (male) & $38(95 \%)$ & $32(78 \%)$ & $33(81 \%)$ & $35(88 \%)$ & $31(78 \%)$ & $28(70 \%)$ & $35(88 \%)$ & $30(73 \%)$ & $35(85 \%)$ \\
\hline BMI $\left(\mathrm{kg} / \mathrm{m}^{2}\right)$ & $26.0(1.8)$ & $26 \cdot 4(2 \cdot 7)$ & $25 \cdot 6(2 \cdot 8)$ & $26 \cdot 3(2 \cdot 7)$ & $25 \cdot 9(2 \cdot 6)$ & $25 \cdot 7(2 \cdot 4)$ & $26.0(2.8)$ & $26 \cdot 1(2 \cdot 7)$ & $26 \cdot 3(3 \cdot 4)$ \\
\hline \multicolumn{10}{|l|}{ Ethnic origin } \\
\hline White & $40(100 \%)$ & $41(100 \%)$ & $41(100 \%)$ & $39(98 \%)$ & $38(95 \%)$ & 39 (98\%) & $39(98 \%)$ & $40(98 \%)$ & $40(98 \%)$ \\
\hline Other & $0(0 \%)$ & $0(0 \%)$ & $0(0 \%)$ & $1(3 \%)$ & $2(5 \%)$ & $1(3 \%)$ & $1(3 \%)$ & $1(2 \%)$ & $1(2 \%)$ \\
\hline \multicolumn{10}{|l|}{ Smoking status } \\
\hline Current smoker & $6(15 \%)$ & $2(5 \%)$ & $6(15 \%)$ & $5(13 \%)$ & $7(18 \%)$ & $2(5 \%)$ & $5(13 \%)$ & $4(10 \%)$ & $8(20 \%)$ \\
\hline Non-smoker & $16(40 \%)$ & $20(49 \%)$ & $18(44 \%)$ & $21(53 \%)$ & $13(33 \%)$ & $18(45 \%)$ & $12(30 \%)$ & $12(29 \%)$ & $16(39 \%)$ \\
\hline Past smoker & $18(45 \%)$ & $19(46 \%)$ & $17(42 \%)$ & $14(35 \%)$ & $20(50 \%)$ & $20(50 \%)$ & $23(58 \%)$ & $25(61 \%)$ & $17(42 \%)$ \\
\hline Type 2 diabetes & $0(0 \%)$ & $0(0 \%)$ & $0(0 \%)$ & $0(0 \%)$ & $1(3 \%)$ & $0(0 \%)$ & $1(3 \%)$ & $2(5 \%)$ & $1(2 \%)$ \\
\hline \multicolumn{10}{|c|}{ Data are mean $(\mathrm{SD})$ or $\mathrm{n}(\%)$. } \\
\hline
\end{tabular}

\begin{tabular}{|c|c|c|c|c|c|c|c|}
\hline & \multirow[t]{2}{*}{$\mathbf{N}$} & \multirow[t]{2}{*}{ Baseline } & \multirow[t]{2}{*}{ Week 12} & \multirow{2}{*}{$\begin{array}{l}\text { Absolute change from baseline } \\
\text { at week } 12\end{array}$} & \multirow{2}{*}{$\begin{array}{l}\% \text { change from baseline } \\
\text { at week } 12\end{array}$} & \multicolumn{2}{|c|}{$p$ value for $\%$ change from baseline } \\
\hline & & & & & & $\begin{array}{l}\text { TA-8995 } \\
\text { monotherapy } \\
\text { versus placebo }\end{array}$ & $\begin{array}{l}\text { TA- } 8995 \text { plus } \\
\text { statin versus } \\
\text { statin alone }\end{array}$ \\
\hline \multicolumn{8}{|l|}{ LDL cholesterol ( $\mathrm{mmol} / \mathrm{L})$} \\
\hline Placebo & 36 & $3.8(0.5)$ & $3 \cdot 7(0.5)$ & $-0.05,-0.09(-0.34$ to 0.22$)$ & $0.8(-3.4$ to 4.9$)$ & NA & NA \\
\hline 1 mg TA-8995 & 36 & $3.6(0.6)$ & $2.6(0.6)$ & $-0.98,-1.03(-1.36$ to -0.55$)$ & $-27 \cdot 4(-31 \cdot 5$ to $-23 \cdot 2)$ & $<0.0001$ & NA \\
\hline $2 \cdot 5 \mathrm{mg}$ TA-8995 & 38 & $3 \cdot 6(0.5)$ & $2 \cdot 4(0 \cdot 7)$ & $-1.15,-1.17(-1.52$ to -0.64$)$ & $-32 \cdot 7(-36.8$ to -28.6$)$ & $<0.0001$ & NA \\
\hline 5 mg TA-8995 & 39 & $3.5(0.6)$ & $1.9(0.5)$ & $-1 \cdot 62,-1.66(-2 \cdot 04$ to $-1 \cdot 21)$ & $-45 \cdot 3(-49 \cdot 3$ to $-41 \cdot 3)$ & $<0.0001$ & NA \\
\hline $10 \mathrm{mg}$ TA-8995 & 35 & $3.5(0.6)$ & $1.9(0.5)$ & $-1 \cdot 62,-1.66(-1.92$ to $-1 \cdot 14)$ & $-45 \cdot 3(-49 \cdot 4$ to $-41 \cdot 1)$ & $<0.0001$ & NA \\
\hline $20 \mathrm{mg}$ atorvastatin & 37 & $3 \cdot 8(0 \cdot 4)$ & $2 \cdot 0(0 \cdot 4)$ & $-1 \cdot 77,-1 \cdot 71(-2 \cdot 17$ to $-1 \cdot 50)$ & $-45 \cdot 4(-49 \cdot 5$ to $-41 \cdot 3)$ & NA & NA \\
\hline $20 \mathrm{mg}$ atorvastatin plus $10 \mathrm{mg}$ TA-8995 & 38 & $3.5(0.6)$ & $1.1(0.4)$ & $-2 \cdot 37,-2 \cdot 38(-2 \cdot 82$ to $-2 \cdot 09)$ & $-68 \cdot 2(-72 \cdot 3$ to $-64 \cdot 2)$ & NA & $<0.0001$ \\
\hline $10 \mathrm{mg}$ rosuvastatin & 38 & $3.7(0.6)$ & $2 \cdot 0(0 \cdot 4)$ & $-1 \cdot 72,-1 \cdot 71(-2 \cdot 12$ to $-1 \cdot 29)$ & $-45 \cdot 3(-49 \cdot 4$ to $-41 \cdot 3)$ & NA & NA \\
\hline $10 \mathrm{mg}$ rosuvastatin plus $10 \mathrm{mg}$ TA-8995 & 37 & $3.6(0.6)$ & $1 \cdot 3(0 \cdot 4)$ & $-2 \cdot 26,-2 \cdot 26(-2 \cdot 54$ to $-2 \cdot 02)$ & $-63 \cdot 3(-67 \cdot 4$ to $-59 \cdot 2)$ & NA & $<0.0001$ \\
\hline \multicolumn{8}{|l|}{ HDL cholesterol ( $\mathrm{mmol} / \mathrm{L})$} \\
\hline Placebo & 37 & $1 \cdot 3(0 \cdot 3)$ & $1 \cdot 4(0 \cdot 3)$ & $0.02,0.03(-0.08$ to 0.13$)$ & $2 \cdot 2(-8 \cdot 0$ to $12 \cdot 4)$ & NA & NA \\
\hline 1 mg TA-8995 & 37 & $1 \cdot 3(0 \cdot 2)$ & $2 \cdot 4(0 \cdot 5)$ & $1.02,1.03(0.78$ to 1.16$)$ & $75 \cdot 8(65 \cdot 5$ to $86 \cdot 1)$ & $<0.0001$ & NA \\
\hline $2 \cdot 5 \mathrm{mg}$ TA-8995 & 38 & $1.4(0 \cdot 3)$ & $3 \cdot 0(0 \cdot 7)$ & $1.66,1.65(1.40$ to 1.97$)$ & $124 \cdot 3(114.0$ to $134 \cdot 5)$ & $<0.0001$ & NA \\
\hline 5 mg TA-8995 & 39 & $1 \cdot 3(0 \cdot 2)$ & $3 \cdot 3(0 \cdot 5)$ & $2.01,1.99(1.68$ to 2.28$)$ & $157 \cdot 1(147 \cdot 0$ to $167 \cdot 1)$ & $<0.0001$ & NA \\
\hline $10 \mathrm{mg}$ TA-8995 & 35 & $1 \cdot 3(0 \cdot 3)$ & $3.6(0.6)$ & $2.30,2.17(1.94$ to 2.59$)$ & $179 \cdot 0(168 \cdot 6$ to $189 \cdot 4)$ & $<0.0001$ & NA \\
\hline $20 \mathrm{mg}$ atorvastatin & 37 & $1.4(0.2)$ & $1 \cdot 4(0 \cdot 3)$ & $0.01,0.03(-0.10$ to 0.08$)$ & $5 \cdot 7(-4 \cdot 7$ to $16 \cdot 0)$ & NA & NA \\
\hline $20 \mathrm{mg}$ atorvastatin plus $10 \mathrm{mg}$ TA-8995 & 38 & $1 \cdot 3(0 \cdot 3)$ & $3.3(0.5)$ & $1.94,1.98(1.74$ to 2.18$)$ & $152 \cdot 1(141 \cdot 9$ to $162 \cdot 2)$ & NA & $<0.0001$ \\
\hline $10 \mathrm{mg}$ rosuvastatin & 38 & $1 \cdot 3(0 \cdot 3)$ & $1 \cdot 4(0 \cdot 3)$ & $0.07,0.04(-0.06$ to 0.23$)$ & $7 \cdot 1(-3 \cdot 0$ to $17 \cdot 2)$ & NA & NA \\
\hline $10 \mathrm{mg}$ rosuvastatin plus $10 \mathrm{mg}$ TA-8995 & 38 & $1 \cdot 4(0 \cdot 3)$ & $3.4(0.5)$ & $2 \cdot 07,2 \cdot 04$ (1.76 to $2 \cdot 38)$ & $157 \cdot 5(147 \cdot 4$ to $167 \cdot 6)$ & NA & $<0.0001$ \\
\hline
\end{tabular}




\section{Outcomes}

The coprimary efficacy outcome parameters were percent change in LDL cholesterol and HDL cholesterol levels at week 12 compared with baseline. Secondary efficacy assessments included fasted total cholesterol, triglycerides, apolipoproteins A-I, B, and E and lipoprotein(a). Additional endpoints included CETP plasma concentrations, CETP activity, and homeostatic model assessment of insulin resistance (HOMA-IR). Cholesterol efflux capacity, an exploratory outcome, was measured according to the method described by Khera and colleagues ${ }^{6,7}$ in patients receiving either placebo, $1 \mathrm{mg}$ TA-8995, $10 \mathrm{mg}$ TA-8995, or $10 \mathrm{mg}$ TA-8995 plus $10 \mathrm{mg}$ rosuvastatin.

Safety was assessed throughout the trial by monitoring adverse events, concomitant drug use, 12-lead electrocardiographs, vital signs, laboratory safety assessments,

\begin{tabular}{|c|c|c|c|c|c|c|c|}
\hline & \multirow[t]{2}{*}{$\mathbf{N}$} & \multirow[t]{2}{*}{ Baseline } & \multirow[t]{2}{*}{ Week 12} & \multirow[t]{2}{*}{$\begin{array}{l}\text { Absolute change from baseline at } \\
\text { week } 12\end{array}$} & \multirow[t]{2}{*}{$\begin{array}{l}\% \text { change from } \\
\text { baseline at week } 12\end{array}$} & \multicolumn{2}{|c|}{$\begin{array}{l}p \text { value for \% change from } \\
\text { baseline }\end{array}$} \\
\hline & & & & & & $\begin{array}{l}\text { TA-8995 } \\
\text { monotherapy } \\
\text { versus placebo }\end{array}$ & $\begin{array}{l}\text { TA- } 8995 \text { + statin } \\
\text { versus statin } \\
\text { alone }\end{array}$ \\
\hline \multicolumn{8}{|l|}{ Triglycerides (mmol/L) } \\
\hline Placebo & 37 & $1.4(0 \cdot 6)$ & $1 \cdot 3(0 \cdot 6)$ & $-0.07,-0.12(-0.36$ to 0.07$)$ & $-3 \cdot 0(-13 \cdot 3,7 \cdot 4)$ & NA & NA \\
\hline $1 \mathrm{mg}$ TA-8995 & 37 & $1.4(0.5)$ & $1.1(0.4)$ & $-0.30,-0.19(-0.46$ to -0.03$)$ & $-17 \cdot 5(-27 \cdot 9,-7 \cdot 1)$ & 0.0524 & NA \\
\hline $2.5 \mathrm{mg}$ TA-8995 & 38 & $1.4(0.8)$ & $1 \cdot 2(0 \cdot 4)$ & $-0.26,-0.12(-0.43$ to 0.05$)$ & $-11 \cdot 8(-22 \cdot 1,-1 \cdot 5)$ & 0.2347 & NA \\
\hline 5 mg TA-8995 & 39 & $1 \cdot 7(1 \cdot 0)$ & $1 \cdot 3(0 \cdot 5)$ & $-0.38,-0.14(-0.64$ to 0.06$)$ & $-7 \cdot 6(-17 \cdot 8,2 \cdot 5)$ & 0.5274 & NA \\
\hline 10 mg TA-8995 & 35 & $1 \cdot 7(0 \cdot 7)$ & $1 \cdot 5(0 \cdot 9)$ & $-0.19,-0.12(-0.59$ to 0.16$)$ & $-5 \cdot 7(-16 \cdot 3,4 \cdot 9)$ & $0 \cdot 7179$ & NA \\
\hline $20 \mathrm{mg}$ atorvastatin & 37 & $1.4(0.5)$ & $1.0(0 \cdot 3)$ & $-0.39,-0.34(-0.51$ to -0.25$)$ & $-25 \cdot 2(-35 \cdot 6,-14 \cdot 7)$ & NA & NA \\
\hline $20 \mathrm{mg}$ atorvastatin plus $10 \mathrm{mg}$ TA-8995 & 38 & $1.3(0.6)$ & $1.0(0.4)$ & $-0.32,-0.24(-0.49$ to 0.02$)$ & $-18 \cdot 0(-28 \cdot 3,-7 \cdot 7)$ & NA & 0.3355 \\
\hline $10 \mathrm{mg}$ rosuvastatin & 38 & $1 \cdot 6(0 \cdot 7)$ & $1 \cdot 3(1 \cdot 2)$ & $-0.28,-0.38(-0.69$ to -0.09$)$ & $-14 \cdot 9(-25 \cdot 2,-4 \cdot 7)$ & NA & NA \\
\hline $10 \mathrm{mg}$ rosuvastatin plus $10 \mathrm{mg}$ TA-8995 & 38 & $1.4(0.6)$ & $1 \cdot 0(0 \cdot 3)$ & $-0.34,-0.30(-0.58$ to -0.01$)$ & $-11 \cdot 5(-21 \cdot 7,-1 \cdot 2)$ & NA & 0.6408 \\
\hline \multicolumn{8}{|l|}{ Total cholesterol ( $\mathrm{mmol} / \mathrm{L})$} \\
\hline Placebo & 37 & $5 \cdot 8(0 \cdot 5)$ & $5 \cdot 8(0 \cdot 6)$ & $-0.03,-0.05(-0.34$ to 0.28$)$ & $1 \cdot 1(-2 \cdot 6,4 \cdot 7)$ & NA & NA \\
\hline 1 mg TA-8995 & 37 & $5 \cdot 6(0.7)$ & $5 \cdot 5(0.9)$ & $-0.11,-0.13(-0.52$ to 0.36$)$ & $-2 \cdot 0(-5 \cdot 6,1 \cdot 7)$ & 0.2507 & NA \\
\hline $2.5 \mathrm{mg}$ TA-8995 & 38 & $5 \cdot 6(0.7)$ & $5 \cdot 9(1.0)$ & $0.31,0.43(-0.31$ to 0.98$)$ & $5 \cdot 8(2 \cdot 1,9 \cdot 4)$ & 0.0756 & NA \\
\hline 5 mg TA-8995 & 39 & $5 \cdot 6(0 \cdot 7)$ & $5 \cdot 7(0 \cdot 8)$ & $0 \cdot 11,0.16(-0.39$ to 0.57$)$ & $2 \cdot 2(-1 \cdot 3,5 \cdot 8)$ & 0.6560 & NA \\
\hline 10 mg TA-8995 & 35 & $5 \cdot 7(0.6)$ & $6 \cdot 1(0 \cdot 7)$ & $0.44,0.47(-0.15$ to 0.99$)$ & $8 \cdot 5(4 \cdot 8,12 \cdot 1)$ & 0.0056 & NA \\
\hline $20 \mathrm{mg}$ atorvastatin & 37 & $5 \cdot 9(0.5)$ & $3.9(0.5)$ & $-1.97,-2.02(-2.49$ to -1.53$)$ & $-31 \cdot 7(-35 \cdot 4,-28 \cdot 0)$ & NA & NA \\
\hline $20 \mathrm{mg}$ atorvastatin plus $10 \mathrm{mg}$ TA-8995 & 38 & $5 \cdot 5(0 \cdot 7)$ & $4 \cdot 8(0 \cdot 6)$ & $-0.69,-0.77(-1.12$ to -0.36$)$ & $-13 \cdot 2(-16 \cdot 8,-9 \cdot 6)$ & NA & $<0.0001$ \\
\hline $10 \mathrm{mg}$ rosuvastatin & 38 & $5 \cdot 8(0 \cdot 7)$ & $4 \cdot 0(0 \cdot 5)$ & $-1.88,-1.90(-2.28$ to -1.58$)$ & $-30 \cdot 7(-34 \cdot 3,-27 \cdot 1)$ & NA & NA \\
\hline $10 \mathrm{mg}$ rosuvastatin plus $10 \mathrm{mg}$ TA-8995 & 38 & $5 \cdot 6(0 \cdot 7)$ & $5 \cdot 2(0 \cdot 8)$ & $-0.46,-0.47(-0.90$ to 0.05$)$ & $-8 \cdot 2(-11 \cdot 8,-4 \cdot 6)$ & NA & $<0.0001$ \\
\hline \multicolumn{8}{|l|}{ Apolipoprotein A-1 (g/L) } \\
\hline Placebo & 37 & $1 \cdot 4(0 \cdot 2)$ & $1 \cdot 5(0 \cdot 2)$ & $0.02,0.05(-0.11$ to 0.12$)$ & $2 \cdot 5(-2 \cdot 4,7 \cdot 4)$ & NA & NA \\
\hline $1 \mathrm{mg}$ TA-8995 & 37 & $1 \cdot 4(0 \cdot 2)$ & $1 \cdot 9(0 \cdot 3)$ & $0.45,0.45(-0.28$ to 0.61$)$ & $31 \cdot 2(26 \cdot 2,36 \cdot 1)$ & $<0.0001$ & NA \\
\hline $2.5 \mathrm{mg}$ TA-8995 & 38 & $1 \cdot 5(0 \cdot 2)$ & $2 \cdot 2(0 \cdot 4)$ & $0.69,0.73(0.49$ to 0.85$)$ & $49 \cdot 0(44 \cdot 1,53 \cdot 9)$ & $<0.0001$ & NA \\
\hline 5 mg TA-8995 & 39 & $1 \cdot 4(0 \cdot 2)$ & $2 \cdot 2(0 \cdot 3)$ & $0.81,0.82(0.64$ to 0.95$)$ & $57 \cdot 5(52 \cdot 7,62 \cdot 3)$ & $<0.0001$ & NA \\
\hline 10 mg TA-8995 & 35 & $1 \cdot 4(0 \cdot 2)$ & $2 \cdot 3(0 \cdot 2)$ & $0.90,0.86(0.73$ to 1.03$)$ & $63 \cdot 4(58 \cdot 3,68 \cdot 4)$ & $<0.0001$ & NA \\
\hline $20 \mathrm{mg}$ atorvastatin & 37 & $1 \cdot 5(0 \cdot 2)$ & $1 \cdot 5(0 \cdot 2)$ & $-0.03,-0.04(-0.15$ to 0.10$)$ & $0 \cdot 8(-4 \cdot 2,5 \cdot 8)$ & NA & NA \\
\hline $20 \mathrm{mg}$ atorvastatin plus $10 \mathrm{mg}$ TA-8995 & 38 & $1 \cdot 4(0 \cdot 2)$ & $2 \cdot 1(0 \cdot 2)$ & $0.74,0.72(0.62$ to 0.91$)$ & $52 \cdot 7(47 \cdot 8,57 \cdot 5)$ & NA & $<0.0001$ \\
\hline $10 \mathrm{mg}$ rosuvastatin & 38 & $1 \cdot 4(0 \cdot 2)$ & $1 \cdot 5(0 \cdot 2)$ & $0.04,0.05(-0.06$ to 0.15$)$ & $4 \cdot 3(-0.6,9 \cdot 2)$ & NA & NA \\
\hline 10 mg rosuvastatin plus $10 \mathrm{mg}$ TA-8995 & 38 & $1 \cdot 4(0 \cdot 2)$ & $2 \cdot 2(0 \cdot 2)$ & $0.77,0.75(0.66$ to 0.88$)$ & $55 \cdot 8(50 \cdot 9,60 \cdot 6)$ & NA & $<0.0001$ \\
\hline \multicolumn{8}{|l|}{ Apolipoprotein B (g/L) } \\
\hline Placebo & 37 & $1 \cdot 0(0 \cdot 1)$ & $1 \cdot 0(0 \cdot 1)$ & $-0.01,-0.02(-0.09$ to 0.06$)$ & $1 \cdot 1(-2 \cdot 5,4 \cdot 7)$ & NA & NA \\
\hline 1 mg TA-8995 & 37 & $1 \cdot 0(0 \cdot 2)$ & $0.8(0 \cdot 1)$ & $-0 \cdot 20,-0.18(-0 \cdot 31$ to $-0 \cdot 11)$ & $-20 \cdot 0(-23 \cdot 6,-16 \cdot 4)$ & $<0.0001$ & NA \\
\hline $2.5 \mathrm{mg}$ TA-8995 & 38 & $1 \cdot 0(0 \cdot 2)$ & $0 \cdot 7(0 \cdot 1)$ & $-0.25,-0.23(-0.33$ to -0.14$)$ & $-24 \cdot 6(-28 \cdot 2,-21 \cdot 0)$ & $<0.0001$ & NA \\
\hline 5 mg TA-8995 & 39 & $1.0(0 \cdot 2)$ & $0 \cdot 7(0 \cdot 1)$ & $-0.35,-0.37(-0.45$ to -0.24$)$ & $-33 \cdot 6(-37 \cdot 1,-30 \cdot 1)$ & $<0.0001$ & NA \\
\hline 10 mg TA-8995 & 35 & $1 \cdot 0(0 \cdot 2)$ & $0.6(0 \cdot 1)$ & $-0.35,-0.34(-0.44$ to -0.21$)$ & $-33 \cdot 7(-37 \cdot 3,-30 \cdot 0)$ & $<0.0001$ & NA \\
\hline $20 \mathrm{mg}$ atorvastatin & 37 & $1.0(0.1)$ & $0.6(0.1)$ & $-0.40,-0.41(-0.47$ to -0.31$)$ & $-37 \cdot 4(-41 \cdot 0,-33 \cdot 8)$ & NA & NA \\
\hline $20 \mathrm{mg}$ atorvastatin plus $10 \mathrm{mg}$ TA-8995 & 38 & $1 \cdot 0(0 \cdot 2)$ & $0 \cdot 5(0 \cdot 1)$ & $-0.51,-0.51(-0.61$ to -0.41$)$ & $-50 \cdot 1(-53 \cdot 7,-46 \cdot 6)$ & NA & $<0.0001$ \\
\hline $10 \mathrm{mg}$ rosuvastatin & 38 & $1.0(0.1)$ & $0.7(0.1)$ & $-0.37,-0.36(-0.44$ to -0.27$)$ & $-34 \cdot 5(-38 \cdot 0,-30 \cdot 9)$ & NA & NA \\
\hline \multirow[t]{2}{*}{$10 \mathrm{mg}$ rosuvastatin plus $10 \mathrm{mg}$ TA-8995 } & 38 & $1 \cdot 0(0 \cdot 1)$ & $0 \cdot 5(0 \cdot 1)$ & $-0.47,-0.45(-0.53$ to -0.39$)$ & $-46 \cdot 3(-49 \cdot 9,-42 \cdot 8)$ & NA & $<0.0001$ \\
\hline & & & & & & \multicolumn{2}{|c|}{ (Table 3 continues on next page) } \\
\hline
\end{tabular}


and physical examinations. Additional safety assessments included plasma aldosterone, salivary cortisol, high-sensitivity C-reactive protein, and endothelin-1 concentrations. Blood samples were also collected for pharmacokinetic analysis.

\section{Statistical analysis}

The primary efficacy analysis of the percent change in HDL cholesterol and LDL cholesterol from baseline to week 12 was done with a restricted maximum likelihood mixed model for repeated measures approach. Analysis included fixed categorical effects of treatment, visit and treatment-by-visit interaction, and a continuous fixed covariate for baseline HDL cholesterol or LDL cholesterol score. Least-squares means, standard errors and two-tailed 95\% confidence intervals for each treatment group and for pairwise comparisons between TA- 8995 doses and placebo, between TA-8995 plus atorvastatin and atorvastatin alone, and between TA-8995 plus rosuvastatin and rosuvastatin alone were provided. Because there were two coprimary efficacy variables, we used a closed testing procedure to control the family-wise error. No interim analyses were planned or undertaken.

The sample size of 37 completed patients per treatment group was intended to provide $88 \%$ power to detect a $22 \cdot 5 \%$ (standard deviation [SD] 30\%) increase in HDL cholesterol compared with statin alone. This sample size with an assumed 10\% (SD 15\%) greater decrease in LDL cholesterol for the investigational product compared with placebo was expected to provide a power of $80 \%$. All tests were two-sided with a significance of $0 \cdot 05$. To allow for a $10-15 \%$ dropout rate, 378 patients were planned. All analyses were done with SAS (version 9.2).

The trial protocol was registered on ClinicalTrials.gov, number NCT01970215.

\section{Role of the funding source}

The funder was involved in the design of the study and in collection, management, and analysis of the data, in conjunction with the steering committee. The initial draft of the report was prepared by PR and PJB. GKH in conjunction with the other authors had the main responsibility for the decision to submit for publication. The authors vouch for the accuracy and completeness of the data and analyses as presented.

\section{Results}

Between August, 2013, and July, 2014, 364 patients were randomly assigned and received at least one dose of study treatment, and 337 (93\%) completed the trial (figure 1). Primary outcome data (LDL cholesterol and

\begin{tabular}{|c|c|c|c|c|c|c|c|}
\hline & \multirow[t]{2}{*}{$\mathbf{N}$} & \multirow[t]{2}{*}{ Baseline } & \multirow[t]{2}{*}{ Week 12} & \multirow[t]{2}{*}{$\begin{array}{l}\text { Absolute change from baseline at } \\
\text { week } 12\end{array}$} & \multirow[t]{2}{*}{$\begin{array}{l}\% \text { change from } \\
\text { baseline at week } 12\end{array}$} & \multicolumn{2}{|c|}{$\begin{array}{l}p \text { value for \% change from } \\
\text { baseline }\end{array}$} \\
\hline & & & & & & $\begin{array}{l}\text { TA-8995 } \\
\text { monotherapy } \\
\text { versus placebo }\end{array}$ & $\begin{array}{l}\text { TA- } 8995+\text { statin } \\
\text { versus statin } \\
\text { alone }\end{array}$ \\
\hline \multicolumn{8}{|l|}{ (Continued from previous page) } \\
\hline \multicolumn{8}{|l|}{ Apolipoprotein E (g/L) } \\
\hline Placebo & 37 & $0.04(0.01)$ & $0.04(0.01)$ & $0.001,0.000(-0.002$ to 0.003$)$ & $3 \cdot 2(-7 \cdot 8,14 \cdot 3)$ & NA & NA \\
\hline 1 mg TA-8995 & 37 & $0.04(0.01)$ & $0.05(0.02)$ & $0.008,0.004(-0.001$ to 0.012$)$ & $19 \cdot 3(8 \cdot 2,30 \cdot 4)$ & 0.0446 & NA \\
\hline $2.5 \mathrm{mg}$ TA-8995 & 38 & $0.04(0.01)$ & $0.05(0.02)$ & $0.012,0.008(0.003$ to 0.018$)$ & $33 \cdot 4(22 \cdot 3,44 \cdot 4)$ & 0.0002 & NA \\
\hline $5 \mathrm{mg}$ TA-8995 & 39 & $0.04(0.01)$ & $0.05(0.02)$ & $0.012,0.010(0.004$ to 0.024$)$ & $37 \cdot 8(27 \cdot 0,48 \cdot 6)$ & $<0.0001$ & NA \\
\hline $10 \mathrm{mg}$ TA-8995 & 35 & $0.04(0.01)$ & $0.06(0.02)$ & $0.020,0.017(0.009$ to 0.028$)$ & $57 \cdot 0(45 \cdot 8,68 \cdot 2)$ & $<0.0001$ & NA \\
\hline $20 \mathrm{mg}$ atorva & 37 & $0.04(0.01)$ & $0.03(0.01)$ & $-0.008,-0.008(-0.010$ to -0.004$)$ & $-20 \cdot 7(-31 \cdot 8,-9 \cdot 5)$ & NA & NA \\
\hline $20 \mathrm{mg}$ atorva $+10 \mathrm{mg}$ TA-8995 & 38 & $0.04(0.01)$ & $0.04(0.02)$ & $0.006,0.006(-0.005$ to 0.013$)$ & $17 \cdot 9(7 \cdot 0,28 \cdot 8)$ & NA & $<0.0001$ \\
\hline $10 \mathrm{mg}$ rosuvastatin & 38 & $0.04(0.01)$ & $0.03(0.01)$ & $-0.007,-0.007(-0.012$ to -0.002$)$ & $-15 \cdot 9(-26 \cdot 7,-4 \cdot 9)$ & NA & NA \\
\hline $10 \mathrm{mg}$ rosuvastatin plus $10 \mathrm{mg}$ TA-8995 & 38 & $0.04(0.01)$ & $0.06(0.02)$ & $0.019,0.017(0.008$ to 0.028$)$ & $54 \cdot 6(43 \cdot 7,65 \cdot 5)$ & NA & $<0.0001$ \\
\hline \multicolumn{8}{|l|}{ Lipoprotein(a) (nmol/L) } \\
\hline Placebo & 37 & $51 \cdot 8(61 \cdot 8)$ & $49 \cdot 4(61 \cdot 9)$ & $-2 \cdot 4,-1 \cdot 0(-7$ to 0$)$ & $-1 \cdot 8(-10 \cdot 7$ to $7 \cdot 2)$ & NA & NA \\
\hline 1 mg TA-8995 & 37 & $47 \cdot 3(55 \cdot 5)$ & $39 \cdot 5(55 \cdot 4)$ & $-7 \cdot 8,-5 \cdot 0(-10$ to -2$)$ & $-29 \cdot 5(-38 \cdot 6$ to $-20 \cdot 4)$ & $<0.0001$ & NA \\
\hline $2.5 \mathrm{mg}$ TA-8995 & 38 & $44 \cdot 6(53 \cdot 2)$ & $33 \cdot 6(44 \cdot 1)$ & $-11 \cdot 0,-5 \cdot 5(-16$ to 0$)$ & $-26 \cdot 7(-35 \cdot 7$ to $-17 \cdot 7)$ & 0.0001 & NA \\
\hline 5 mg TA-8995 & 39 & $42 \cdot 2(54 \cdot 3)$ & $23 \cdot 7(37 \cdot 7)$ & $-18 \cdot 5,-11 \cdot 0(-32$ to -1$)$ & $-36 \cdot 9(-45 \cdot 7$ to $-28 \cdot 1)$ & $<0.0001$ & NA \\
\hline 10 mg TA-8995 & 35 & $44 \cdot 4(65 \cdot 6)$ & $27 \cdot 6(48 \cdot 1)$ & $-16 \cdot 8,-10 \cdot 0(-25$ to 0$)$ & $-33 \cdot 4(-42 \cdot 5$ to $-24 \cdot 4)$ & $<0.0001$ & NA \\
\hline $20 \mathrm{mg}$ atorvastatin & 37 & $31 \cdot 6(41 \cdot 3)$ & $30 \cdot 1(38 \cdot 9)$ & $-1 \cdot 5,-1 \cdot 0(-3$ to 1$)$ & $-3 \cdot 6(-12 \cdot 7$ to $5 \cdot 5)$ & NA & NA \\
\hline $20 \mathrm{mg}$ atorvastatin plus $10 \mathrm{mg}$ TA- 8995 & 38 & $36 \cdot 6(42 \cdot 7)$ & $28 \cdot 5(40 \cdot 5)$ & $-8 \cdot 1,-3 \cdot 5(-11$ to 0$)$ & $-25 \cdot 0(-33 \cdot 8$ to $-16 \cdot 1)$ & NA & 0.0011 \\
\hline 10 mg rosuvastatin & 38 & $38 \cdot 8(54 \cdot 8)$ & $37.5(58 \cdot 0)$ & $-1 \cdot 3,0 \cdot 0(-3$ to 0$)$ & $-7 \cdot 9(-16 \cdot 8$ to $1 \cdot 0)$ & NA & NA \\
\hline $10 \mathrm{mg}$ rosuvastatin plus $10 \mathrm{mg}$ TA-8995 & 38 & $62 \cdot 3(74 \cdot 4)$ & $55 \cdot 9(78.6)$ & $-6 \cdot 3,-3 \cdot 0(-17$ to 0$)$ & $-25 \cdot 4(-34 \cdot 3$ to $-16 \cdot 5)$ & NA & 0.0064 \\
\hline
\end{tabular}




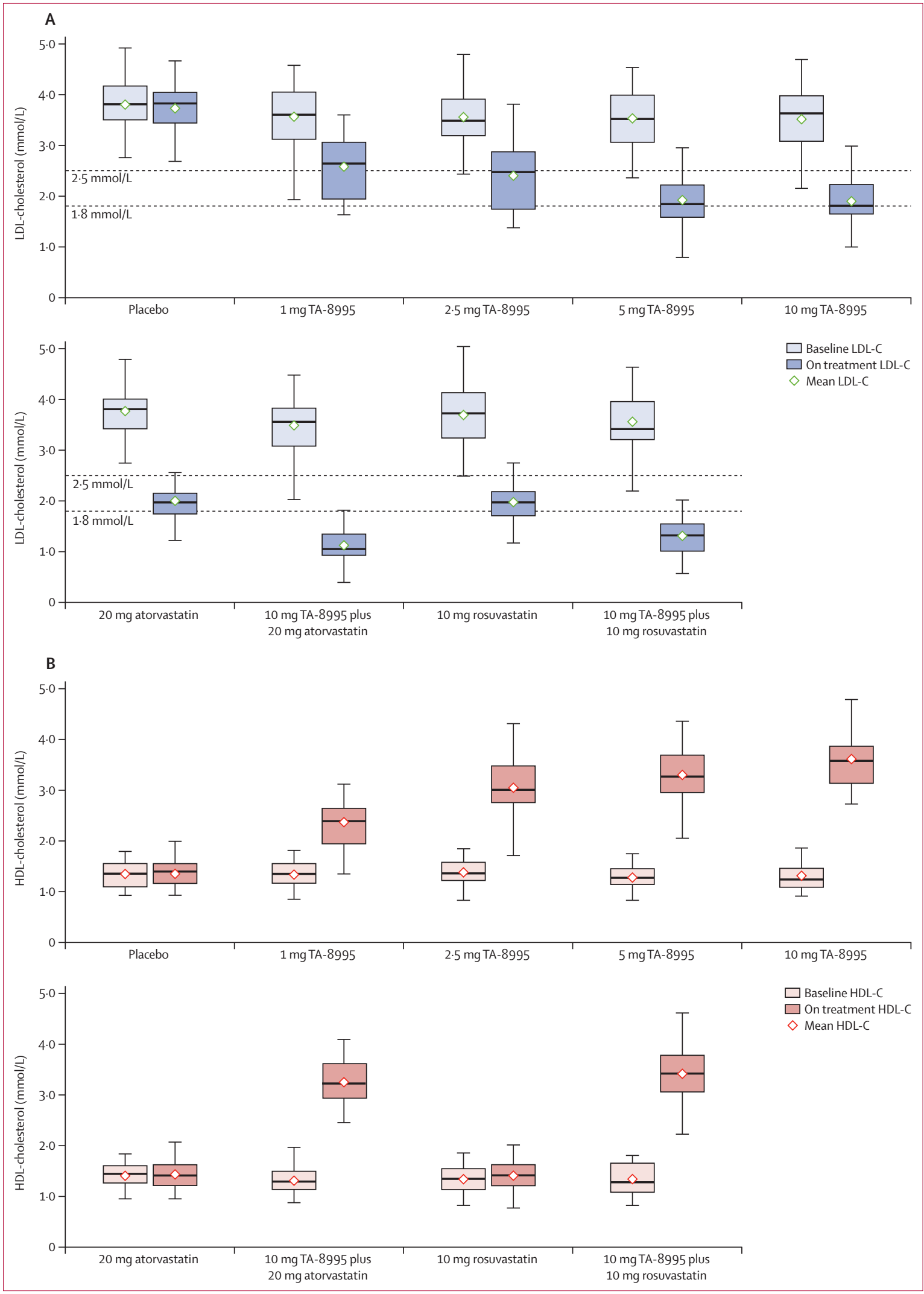

Figure 2: Baseline and week 12 data for $\mathrm{LDL}(\mathrm{A})$ and HDL (B)

Boxes show the 25th and 75th percentiles, whiskers show the minimum and maximum values, horizontal lines show the median, and green circles show the mean. The data only include patients who had both baseline and week 12 data. The changes from baseline for all active treatments showed significant differences from placebo at week 12 $(\mathrm{p}<0.0001)$. 


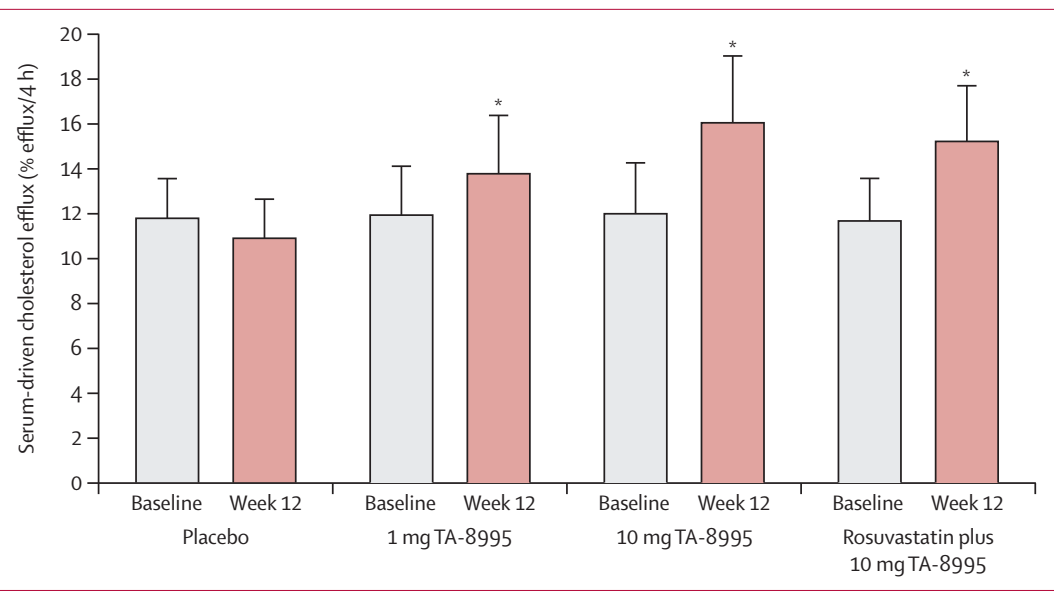

Figure 3: Baseline and week 12 data for serum-driven cholesterol efflux

Bars are means and error bars are standard deviations. The baseline data only include patients who had both baseline and week 12 data. The changes from baseline for all active treatments showed significant differences from placebo at week 12 ( $\left.{ }^{*} \mathrm{p}<0 \cdot 0001\right)$.
HDL cholesterol levels at week 12) were available in 35 to 38 patients per treatment group. Table 1 shows baseline characteristics across all treatment groups. Most participants were white men with a mean age of 65 years (range 22-75). Mean baseline LDL cholesterol concentration was $3.60 \mathrm{mmol} / \mathrm{L}$ (SD 0.57 ) and HDL cholesterol was $1.35 \mathrm{mmol} / \mathrm{L}(0 \cdot 26)$ and these did not differ across treatment groups (table 1 ).

Table 2 shows the primary efficacy outcomes. At week 12, LDL cholesterol concentrations were reduced significantly by $27.4 \%$ in patients who received $1 \mathrm{mg}$ TA- $8995,32.7 \%$ in those who received the $2 \cdot 5 \mathrm{mg}$ dose, $45 \cdot 3 \%$ in those given the $5 \mathrm{mg}$ dose, and $45.3 \%$ in those given the $10 \mathrm{mg}$ dose $(\mathrm{p}<0.0001$ for all). A daily dose of $20 \mathrm{mg}$ atorvastatin resulted in a $45.4 \%$ decrease in LDL cholesterol, whereas we noted a $68 \cdot 2 \%$ decrease in patients given $10 \mathrm{mg}$ TA- 8995 plus atorvastatin $20 \mathrm{mg}(\mathrm{p}<0 \cdot 0001)$, which translates into an additional $50 \cdot 2 \%$ reduction in LDL cholesterol in patients randomly assigned to combination therapy. We noted similar results in patients given $10 \mathrm{mg}$ rosuvastatin (LDL cholesterol decrease $45.3 \%$ ) or $10 \mathrm{mg}$ rosuvastatin plus $10 \mathrm{mg}$ TA-8995 (LDL cholesterol decrease of $63.3 \%$ ), which corresponds to an additional $39.8 \%$ lowering of LDL cholesterol in patients given TA-8995 combined with rosuvastatin. Figure 2 shows the results for the primary outcomes. When TA-8995 was provided as monotherapy, $95 \%$ of patients achieved an LDL cholesterol concentration lower than $2.5 \mathrm{mmol} / \mathrm{L}$ at both the daily $5 \mathrm{mg}$ and $10 \mathrm{mg}$ doses, whereas $65 \%$ of patients given the $5 \mathrm{mg}$ dose achieved an LDL cholesterol concentration lower than $1.8 \mathrm{mmol} / \mathrm{L}$ and $63 \%$ of those given the $10 \mathrm{mg}$ dose.

HDL cholesterol was increased significantly from baseline to week 12 by $75.8 \%$ in patients given $1 \mathrm{mg}$ TA-8995 a day, $124.3 \%$ in those given $2.5 \mathrm{mg}, 157.1 \%$ in those given $5 \mathrm{mg}$, and $179.0 \%$ in those given $10 \mathrm{mg}$ $(p<0 \cdot 0001)$. We noted these effects at the first postrandomisation visit (week 4) and the effects remained present throughout the treatment period (data not shown). TA-8995 was equally effective when given as monotherapy or on top of statin treatment. HDL cholesterol increased by $152 \cdot 1 \%$ in patients receiving $10 \mathrm{mg}$ TA- 8995 combined with $20 \mathrm{mg}$ atorvastatin and $157.5 \%$ in patients receiving $10 \mathrm{mg}$ TA-8995 combined with $10 \mathrm{mg}$ rosuvastatin ( $<<0.0001$ for both).

Table 3 shows the secondary efficacy outcomes. TA-8995 had no significant effect on plasma triglyceride or total cholesterol levels. However, monotherapy with TA-8995 resulted in substantial dose-dependent increases in apoA-1 and apoE concentrations, all of which were significant compared with baseline $(p<0 \cdot 0001)$, except for the apoE change in patients given $1 \mathrm{mg}$ TA-8995 $(\mathrm{p}=0 \cdot 0446)$ and $2.5 \mathrm{mg}$ TA-8995 $(\mathrm{p}=0 \cdot 0002)$. Additionally, apoB concentrations were reduced by $20.0 \%$ to $33.7 \%$ in patients receiving TA-8995 as monotherapy $(\mathrm{p}<0 \cdot 0001)$ whereas in patients receiving TA-8995 combined with atorvastatin, concentrations were reduced by $50 \cdot 1 \%$ and in patients receiving TA-8995 combined with rosuvastatin apoB by $46 \cdot 3 \%(\mathrm{p}<0 \cdot 0001)$.

The different doses of TA-8995, either as monotherapy or combined with a statin resulted in reductions in lipoprotein(a) ranging from $26 \cdot 7 \%$ to $36 \cdot 9 \%$ ( $\mathrm{p}<0 \cdot 0064)$, whereas monotherapy with a statin resulted in reductions in lipoprotein(a) of $3 \cdot 6 \%$ and $7.9 \%$ (table 3 ). Monotherapy with TA-8995 reduced CETP activity by up to $84.9 \%$ ( $<<0 \cdot 0001$; appendix)

Serum-mediated cholesterol efflux was measured at baseline and at week 12 as an exploratory outcome. We noted a $7 \%$ reduction in serum-mediated cell cholesterol efflux (figure 3 ) in patients given placebo. By contrast, the ability of serum to promote cholesterol efflux was increased by $16.9 \%(\mathrm{p}<0.0001)$ in patients given $1 \mathrm{mg}$ TA-8995, whereas treatment with the $10 \mathrm{mg}$ dose resulted in a $36.7 \%$ increase in serum-mediated cholesterol efflux $(\mathrm{p}<0 \cdot 0001$; figure 3$)$.

TA-8995 was well tolerated and the percentage of patients withdrawing because of adverse events was low and similar across treatment groups (appendix). The most common adverse events in the TA-8995 monotherapy group were nasopharyngitis and headache. Most (122/127 [96\%]) adverse events were classified as mild or moderate. Eight patients had serious adverse events during the study but none were deemed to be treatment-related. We noted no effect of TA-8995 (whether given as monotherapy or in combination with a statin) on any laboratory safety parameter including serum aldosterone, salivary cortisol, high sensitivity C-reactive protein or endothelin-1. We analysed the data for each treatment group separately and combined for all patients receiving TA-8995 monotherapy (appendix). TA-8995 had no effect on serum electrolyte concentrations or blood pressure (appendix). TA-8995 treatment did not affect HOMA-IR (appendix).

The mean trough concentrations of TA-8995 were the same at weeks 8 and 12, which suggests that steady state conditions had been achieved by week 8 (data not shown). 
After cessation of dosing, concentrations decreased rapidly and by week 20 ( 8 weeks after the last dose), concentrations of TA-8995 (given either as monotherapy or in combination with a statin) were less than $3 \%$ of the trough levels during treatment, which emphasises that TA-8995 does not accumulate during a 12 -week dosing period.

\section{Discussion}

In this phase 2 study we showed that administration of TA-8995, a new CETP inhibitor, reduced LDL cholesterol levels by $45 \cdot 3 \%$ and apoB levels by $33.7 \%$, whereas HDL cholesterol levels increased by up to $179 \cdot 1 \%$ and apoA-1 levels by up to $63.4 \%$. In combination with statins, $10 \mathrm{mg}$ TA-8995 conferred an additional decrease of LDL cholesterol by $39 \cdot 8 \%$ to $50 \cdot 2 \%$ (panel).

CETP promotes the transfer of cholesteryl esters (the main form of cholesterol in plasma) from nonatherogenic HDL particles, where they are formed, to particles in lipoprotein fractions (including LDL) that cause atherosclerosis. Inhibition of CETP blocks this transfer and reduces the concentration of cholesterol not only in LDL, but also in other atherogenic lipoproteins. The hypothesis that CETP inhibition might be antiatherogenic is supported by results of genomic studies showing that carriers of CETP polymorphisms associated with low CETP activity are at a decreased risk of future cardiovascular events. ${ }^{8,9}$

The ILLUMINATE study ${ }^{3}$ was the first clinical trial to address the effect of lowering CETP on cardiovascular disease outcome. In this study, torcetrapib, a CETP inhibitor that reduced LDL cholesterol levels by roughly $25 \%$ and raised HDL cholesterol levels by about $50 \%$, did not reduce cardiovascular risk. In fact, torcetrapib increased both non-fatal and fatal cardiovascular events and also increased death from non-cardiovascular causes. The explanation for the adverse outcome is not fully understood, but could have been the consequence of serious off-target effects of this compound. Investigators noted a significant increase in blood pressure in patients given torcetapib. Results of subsequent studies showed that torcetrapib also increased the synthesis and secretion of both aldosterone and cortisol from adrenal cortical cells in tissue culture and increased expression of endothelin-1 in the artery wall. ${ }^{10,11}$ The presence of these off-target effects made it impossible to draw any meaningful conclusions regarding the possible antiatherogenic potential of CETP inhibition.

TA- 8995 seems to be free of the adverse effects of torcetrapib and, at low doses, effectively reduces LDL cholesterol, apoB, and lipoprotein(a). The magnitude of the reductions induced by treatment with TA-8995 suggests that this drug has the potential to provide substantial reductions in cardiovascular risk. Findings of previous intervention studies have shown that a statin-induced decrease in LDL cholesterol and apoB has a beneficial effect on cardiovascular disease outcome ${ }^{12}$ and the clinical relevance of non-statin induced LDL cholesterol lowering has recently been established in the
Panel: Research in context

\section{Systematic review}

In December, 2014, we searched Pubmed to identify studies published since 2006 in any language on CETP, cardiovascular disease, and (novel) therapeutic agents. The following terms were used: "CETP AND treatment", and "dyslipidemia AND randomised controlled trial". We only included studies in human beings.

\section{Interpretation}

Many patients do not reach optimum LDL cholesterol levels despite a maximally tolerated dose of statins. Further LDL cholesterol lowering is warranted in these individuals and CETP inhibition causes such an effect. Our findings show that TA-8995, a novel CETP inhibitor, has a beneficial effect on lipids and lipoproteins; LDL cholesterol decreased by $45 \cdot 3 \%$ and apoB levels by $33 \cdot 7 \%$, whereas $\mathrm{HDL}$ cholesterol concentrations increased by up to $179 \cdot 1 \%$ and apoA-I by $63.4 \%$. Lastly, cholesterol efflux capacity increased by $36.7 \%$ in patients randomly assigned to $10 \mathrm{mg}$ TA-8995. All these effects were similar in patients on monotherapy or in combination with a statin. No related serious adverse events were reported and the drug was well tolerated. These findings are important because they provide clinicians with the evidence that CETP inhibition with TA-8995 is an effective LDL cholesterol lowering and HDL cholesterol increasing treatment with the aim to prevent cardiovascular disease.

IMPROVE-IT study. ${ }^{13}$ Lipoprotein(a) concentrations are positively associated with incident cardiovascular disease events, but whether lipoprotein(a) lowering results in cardiovascular disease risk reduction is unknown. ${ }^{14}$

Although CETP inhibitors were initially designated HDL cholesterol-increasing agents, TA-8995 potently reduces the concentrations of atherogenic lipoproteins such as LDL, either as monotherapy or in combination with statin treatment. The major increase in concentrations of HDL cholesterol and apoA-1 with TA-8995 might have an additional beneficial effect. The role of HDL cholesterol in cardiovascular disease risk is not completely understood and it remains to be established whether a therapeutic increase of HDL cholesterol and HDL particle numbers will translate into a reduced cardiovascular disease risk. ${ }^{15}$ Dalcetrapib, a rather weak CETP inhibitor that increased HDL cholesterol concentrations by about $30 \%$ and had no effect on LDL cholesterol levels, was not associated with cardiovascular events or cardiovascular-related adverse events. $^{4}$

The failure of dalcetrapib could have been the consequence of the inability of this agent to reduce the levels of LDL cholesterol or to sufficiently stimulate cholesterol efflux. Cholesterol efflux has been studied by Ray and coworkers ${ }^{16}$ who noted that total cholesterol efflux capacity, assessed by the same method used in the present TULIP trial, increased by $9.5 \%$ in patients randomly assigned to receive $600 \mathrm{mg}$ dalcetrapib once a day for 4 weeks. In patients given evacetrapib (at a dose range of 30-500 mg per day) the mean cholesterol efflux increased by $28 \%{ }^{17}$ A daily dose of $10 \mathrm{mg}$ TA- 8995 resulted in a $36.7 \%$ increase in the ability of serum to promote cell cholesterol efflux. Recent evidence that cholesterol efflux capacity has a strong inverse correlation with incident cardiovascular events suggests that this property of TA-8995 might provide additional protection against 
cardiovascular events. ${ }^{18}$ However, the hypothesis that a therapeutic increase of cholesterol efflux affects cardiovascular outcome remains to be validated in clinical studies. It also needs to be established whether a selected patient group characterised by an untoward cardiometabolic background (ie, patients with diabetes with high CETP) might differentially benefit from CETP inhibitor treatment.

CETP inhibitors are lipophilic by nature and it has been recently reported that anacetrapib is retained in adipose tissue and might remain detectable in serum years after discontinuation of dosing. ${ }^{19}$ By contrast, TA-8995 is not retained in adipose tissue and is rapidly eliminated after discontinuation of dosing. Furthermore, TA-8995 was not detected in fat or liver tissue after 9 months chronic dosing of cynomolgus monkeys at a supratherapeutic dose (data not shown).

In conclusion, we report the effects of a new CETP inhibitor that potently lowers the concentrations of LDL cholesterol, apoB, non-HDL cholesterol, and lipoprotein(a) either as monotherapy or in combination with a statin. As a potential additive beneficial effect, TA-8995 induces a significant increase of plasma apoA-I concentrationss and a substantial increase in the ability to promote cholesterol efflux. The translation of the antiatherogenic potential of TA-8995 recorded in this study into a reduction of future cardiovascular events warrants formal testing in a cardiovascular outcome trial.

\section{Contributors}

JJPK, SJHvD, PR, and JF (Dezima, Naarden, the Netherlands) designed the study in collaboration with HBB and PJB. JJPK, HBB, and PJB were members of the steering committee. PR was responsible for the study conduct and coordination of all statistical analyses, data review and interpretation, report review and revisions. This report was mainly written by GKH, PR, PJB, and JJPK, with assistance from SJHvD and $\mathrm{DJR}$, and was critically reviewed and subsequently approved by all authors. The efflux assays were done under supervision of DS and DJR.

\section{Declaration of interests}

GKH reports that his institution has received funding from Dezima, Amgen, Pfizer, Sanofi, Regeneron, AstraZeneca, Genzyme, Cerenis, Synageva, Roche, ISIS pharmaceuticals, Kowa, and Merck for undertaking clinical trials related to various forms of lipid-lowering medication and consulting fees from Amgen, Pfizer, Roche, and Sanofi. JJP reports personal fees from Dezima Pharmaceuticals during the conduct of the study; personal fees from Cerenis, The Medicines Company, CSL Behring, Amgen, Sanofi, Regeneron, Eli Lilly, Genzyme, Aegerion, Esperion, AstraZeneca, Omthera, Pronova, Vascular Biogenics, Boehringer Ingelheim, Catabasis, AtheroNova, UniQure, Novartis, Merck, Isis Pharmaceuticals, and Kowa. PR and JF are employees of Xention, the sponsor of the TULIP study. SJHvD is a managing partner at Forbion Capital Partners, which owns equity in Dezima Pharma. PJB reports fees from Dezima, during the conduct of the study; personal fees from AstraZeneca, AMGEN, Novartis, CSL-Behring, Kowa, Merck, and Sanofi-Regeneron, outside the submitted work and grants and personal fees from Pfizer.

\section{Acknowledgments}

This study was funded by Dezima and undertaken by Xention. The authors thank Samantha Abel (Valley Writing Solutions Limited) for the initial preparation and QC check of the tables and figures; Joost Besseling and Koos Zwinderman for their assistance related to the analyses and preparation of the figures; and Vascular Strategies LLC (Plymouth Meeting, PA, USA) for conduct of the cholesterol efflux studies.

\section{References}

1 Cholesterol Treatment Trialists' (CTT) Collaboration, Baigent C, Blackwell L, Emberson J, et al. Efficacy and safety of more intensive lowering of LDL cholesterol: a meta-analysis of data from 170000 participants in 26 randomised trials. Lancet 2010; 376: $1670-81$.

2 Barter PJ, Rye KA. Cholesteryl ester transfer protein inhibition as a strategy to reduce cardiovascular risk. J Lipid Res 2012; 53: 1755-66.

3 Barter PJ, Caulfield M, Eriksson M, et al, and the ILLUMINATE Investigators. Effects of torcetrapib in patients at high risk for coronary events. N Engl J Med 2007; 357: 2109-22.

4 Schwartz GG, Olsson AG, Abt M, et al, and the dal-OUTCOMES Investigators. Effects of dalcetrapib in patients with a recent acute coronary syndrome. N Engl J Med 2012; 367: 2089-99.

5 Ford J, Lawson M, Fowler D, et al. Tolerability, pharmacokinetics and pharmacodynamics of TA-8995, a selective cholesteryl ester transfer protein (CETP) inhibitor, in healthy subjects. Br J Clin Pharmacol 2014; 78: 498-508.

6 Khera AV, Cuchel M, de la Llera-Moya M, et al. Cholesterol efflux capacity, high-density lipoprotein function, and atherosclerosis. N Engl J Med 2011; 364: 127-35.

7 de la Llera-Moya M, Drazul-Schrader D, Asztalos BF, Cuchel M, Rader DJ, Rothblat GH. The ability to promote efflux via ABCA1 determines the capacity of serum specimens with similar high-density lipoprotein cholesterol to remove cholesterol from macrophages. Arterioscler Thromb Vasc Biol 2010; 30: 796-801.

8 Johannsen TH, Frikke-Schmidt R, Schou J, Nordestgaard BG Tybjærg-Hansen A. Genetic inhibition of CETP, ischemic vascular disease and mortality, and possible adverse effects. J Am Coll Cardiol 2012; 60: 2041-48.

9 Voight BF, Peloso GM, Orho-Melander M, et al. Plasma HDL cholesterol and risk of myocardial infarction: a mendelian randomisation study. Lancet 2012; 380: 572-80.

$10 \mathrm{Hu}$ X, Dietz JD, Xia C, et al. Torcetrapib induces aldosterone and cortisol production by an intracellular calcium-mediated mechanism independently of cholesteryl ester transfer protein inhibition. Endocrinology 2009; 150: 2211-19.

11 Simic B, Hermann M, Shaw SG, et al. Torcetrapib impairs endothelial function in hypertension. Eur Heart J 2012; 33: 1615-24.

12 Boekholdt SM, Arsenault BJ, Mora S, et al. Association of LDL cholesterol, non-HDL cholesterol, and apolipoprotein B levels with risk of cardiovascular events among patients treated with statins: a meta-analysis. JAMA 2012; 307: 1302-09.

13 IMPROVE-IT. Examining outcomes in subjects with acute coronary syndrome: vytorin (ezetimibe/simvastatin) vs simvastatin (P04103). https://clincialtrials.gov/ ct2/show/NCT00202878 (accessed Dec 11, 2014).

14 Nordestgaard BG, Chapman MJ, Ray K, et al, and the European Atherosclerosis Society Consensus Panel. Lipoprotein(a) as a cardiovascular risk factor: current status. Eur Heart J 2010; 31: 2844-53.

15 Rader DJ, Hovingh GK. HDL and cardiovascular disease. Lancet 2014; 384: 618-25.

16 Ray KK, Ditmarsch M, Kallend D, et al, and the dal-ACUTE Investigators. The effect of cholesteryl ester transfer protein inhibition on lipids, lipoproteins, and markers of HDL function after an acute coronary syndrome: the dal-ACUTE randomized trial. Eur Heart J 2014; 35: 1792-800.

17 American Heart Association Scientific Session Meeting, Nov 15-19 2014, Chicago, USA, poster\# 2062 presented Nov 18 2014, https://aha.apprisor.org/epsAbstractAHA.cfm?id=1 (accessed Dec 11, 2014).

18 Rohatgi A, Khera A, Berry JD, et al. HDL Cholesterol Efflux Capacity and Incident Cardiovascular Events. N Engl J Med 2014; 371: 2383-93.

19 Gotto AM Jr, Kher U, Chatterjee MS, et al, and the DEFINE Investigators. Lipids, safety parameters, and drug concentrations after an additional 2 years of treatment with anacetrapib in the DEFINE study. J Cardiovasc Pharmacol Ther 2014; 19: 543-49. 